\title{
Hyperbaric oxygenation and the genic expression related to oxidative stress in the heart of mice during intestinal ischemia and reperfusion ${ }^{1}$
}

Frederico Somaio Neto', Adauto Tsutomo Ikejiri", Paulo Roberto Bertoletto'I", José Carlos Chaves ${ }^{\text {IV }}$, Roberto Teruyav, Djalma José Fagundes ${ }^{\mathrm{VI}}$

'PhD, Associate Professor, Medical School, Universidade Federal da Grande Dourados (UFGD), Brazil. Acquisition, analysis and interpretation of data; technical procedures; statistical analysis; manuscript preparation and writing.

"Msc, Assistant Professor, Medical School, UFGD, Dourados-MS, Brazil. Acquisition, analysis and interpretation of data; technical procedures.

IIIPhD, Associate Professor, Medical School, UFGD, Dourados-MS, Brazil. Acquisition, analysis and interpretation of data, technical procedures.

IVPhD, Assistant Professor, Medical School, UFGD, Dourados-MS, Brazil. Acquisition, analysis and interpretation of data, technical procedures.

vPhD, Associate Professor, Medical School, Universidade Federal do Mato Grosso do Sul (UFMS), Campo Grande-MS, Brazil. Acquisition, analysis and interpretation of data; technical procedures.

VlPhD, Full Professor, Division of Surgical Techniques and Experimental Surgery, Department of Surgery, Universidade Federal de São Paulo (UNIFESP), Brazil. Conception and design of the study, critical revision, final approval.

Abstract

Purpose: To investigate the effects of hyperbaric oxygenation (HBO) on intestinal ischemia and reperfusion (IR) injury, we evaluated the expression of 84 genes related to oxidative stress and the antioxidant response in mouse hearts.

Methods: Four groups were subjected to 60 minutes of intestinal ischemia followed by 60 minutes of reperfusion: IRG, ischemia and reperfusion group without $\mathrm{HBO}$; HBO-IG, which received $\mathrm{HBO}$ during ischemia; $\mathrm{HBO}-\mathrm{RG}$, which received $\mathrm{HBO}$ during reperfusion; and $\mathrm{HBO}-$ $I R G$, which received $\mathrm{HBO}$ during ischemia and reperfusion. The control group (CG) underwent anesthesia and laparotomy and was observed for 120 minutes. The (RT-qPCR) method was applied. Genes with expression levels three times below or above the threshold cycle were considered significantly hypoexpressed or hyperexpressed, respectively (Student's t-test $\mathrm{p}<0.05)$.

Results: Eight genes (9.52\%) were hyperexpressed in the IRG. When the HBO groups were compared to the IRG, we found a decrease in the expression of eight genes in the HBO-IG, five genes in the HBO-RG, and seven genes in the HBO-IRG.

Conclusion: The reduction in the expression of genes related to oxidative stress and antioxidant defense following $\mathrm{HBO}$ in mouse hearts resulting from intestinal IR injury was more favorable during the ischemic period than during the reperfusion period.

Key words: Gene Expression. Reperfusion Injury, Hyperbaric Oxygenation. Oxidative Stress. Mice. 


\section{- Introduction}

Ischemia-reperfusion (IR) injuries with cellular alterations and humoral disorders lead to an imbalance in homeostasis ${ }^{1}$. These injuries occur as a result of infectious processes, arterial trauma, cardiac arrest, stroke, embolism, tumors, transplants, organ resections, myocardial infarction, and cardiovascular surgeries ${ }^{2}$. The involvement of distant organs concomitant with the ischemic site occurs through pro-inflammatory elements and reactive oxygen species (ROS); the most affected organs are the kidneys, liver, lungs, nervous system, and heart ${ }^{2-4}$.

Because $\mathrm{O}_{2}$ deficiency triggers a chain of adverse events, the supply of $\mathrm{O}_{2}$ in a hyperbaric environment seems to be a novel and relevant option to interrupt the sequence of deleterious effects associated with $\mathrm{IR}^{5,6}$.

Hyperbaric oxygenation (HBO) involves the supply of $100 \%$ oxygen $\left(\mathrm{O}_{2}\right)$ in an environment with atmospheric pressure ranging from two to three absoluteatmospheres (ATA). Thus, plasma and body fluids will have an increased $\mathrm{O}_{2}$ concentration, regardless of the hemoglobin saturation, depending on the integrity of vascular circulation ${ }^{7,8}$.

The RT-qPCR (reverse transcriptase quantitative polymerase chain reaction) technique is a technological tool that allows the reliable and rapid quantitative evaluation of the expression of large numbers of genes. We selected genes related to oxidative stress and the antioxidant defense for assessment in isogenic mice ${ }^{9-11}$.

Based on the assumption that gene expression is quantitatively related to the need for the protein that it encodes, the objective of the study was to investigate the expression of genes involved in oxidative stress and antioxidant defense in cardiac tissues (distal lesion) in isogenic mice.

\section{Methods}

The study was approved by the Ethics Committee, Universidade Federal de São Paulo (no 1849010714) and by the Research Ethics Committee, Universidade Federal da Grande Dourados ( $n$ 18/2015).

Thirty male isogenic mice (C57BL/6) from the Center for the Development of Experimental Models in Medicine and Biology (CEDEME - UNIFESP) were housed under controlled temperature and light conditions with a 12:12 hour light: dark cycle and free access to water and pelleted rations for up to 6 hours before the surgical procedures.

\section{Anesthetic and surgical procedures}

The mice were anesthetized intramuscularly with $44 \mathrm{mg} . \mathrm{kg}^{-1}$ of ketamine hydrochloride solution (Ketamina Agener União Química, São Paulo), 2.5 mg. $\mathrm{kg}^{-1}$ of xylazine hydrochloride (Calmium - União Química, São Paulo), and 0.75 mg. $\mathrm{kg}^{-1}$ of acepromazine (Acepran - Rhobifarma, Hortolândia-SP). The control group (CG) was anesthetized, subjected to laparotomy without occlusion of the superior mesenteric vessels, and observed for 120 minutes. The IR group (IRG) was subjected to 60 minutes of superior mesenteric artery occlusion, followed by 60 minutes of reperfusion. Three groups received $\mathrm{HBO}$ as follows: during ischemia (HBO-IG), during reperfusion (HBO-RG), and during ischemia and during reperfusion (HBO-IRG).

\section{Material collection procedure}

Samples were taken from the small intestine and the heart. The fragments of the hearts and the intestinal segments were washed with saline solution, wrapped in labeled aluminum foil, immersed in liquid nitrogen $\left(-196^{\circ} \mathrm{C}\right)$, and sent to the Laboratory 
of Molecular Biology of the Department of Gynecology, UNIFESP, for processing for the gene expression analysis.

\section{Hyperbaric chamber}

The hyperbaric chamber for small animals consisted of a basic cylindrical structure composed of carbon steel with an internal diameter of $50 \mathrm{~cm}$ and an airtight front lid secured by screws for a maximum pressure of $400 \mathrm{kPa}$ or 4 bars and a maximum working temperature of $50^{\circ} \mathrm{C}$.

\section{Hyperbaric oxygenation procedure}

Animals in the IRG did not receive HBO. Animals in the HBO-IG were placed in the chamber immediately after vascular clamping for 60 minutes. Then, the animals were removed from the chamber, the vascular clamp was removed, and reperfusion was performed for sixty minutes at normal atmospheric pressure. The HBO-RG received the procedure during reperfusion, and the $\mathrm{HBO}$-IRG received $\mathrm{HBO}$ during both the ischemia and reperfusion periods.

\section{Procedures for the determination of gene expression}

The $\mathrm{RT}^{2}$ Profiler ${ }^{\mathrm{TM}} \mathrm{PCR}$ array (SABiosciences, Frederick, MD, USA) was performed to evaluate 84 genes related to the effects of oxidative stress and antioxidant defense. RNA was extracted from the samples using the TRIzol reagent (Life Technologies, Grand Island, NY, USA) and purified using an Rneasy Mini Kit (Qiagen Co. Pensilvania, USA). The RNA concentration was determined using a spectrophotometer, and the quality of the results was ensured by performing the same analysis in a $2 \%$ agarose gel. The first complementary DNA (cDNA) strand was synthesized using $1 \mu \mathrm{g}$ of the total RNA and the
$\mathrm{RT}^{2}$ First Strand Kit (SABiosciences). Identical amounts of CDNA and the SYBR ${ }^{\circ}$ Green $\mathrm{qPCR}$ Master Mix (SABiosciences, Qiagen Company) were distributed into each of the 96 wells of a PCR array plate containing specific genes. Quantitative PCR was performed according to the manufacturer's instructions with 5 endogenous control genes used to measure the PCR array information (ACTB, Gapdh, Hsp90a B1, Hprt1, and Gusb) and a negative control to detect contamination. Replicate positive PCR controls (PPCs) were used to determine the efficiency of the polymerase chain reaction. These controls used a pre-defined artificial DNA sequence in the detection process. Replicate control wells (reverse transcription controls (RTCS) and PPCS) were also included to evaluate the inter-well and intra-plate consistency. The device software (MxPro Equipment Real Time Systems, Stratagene, GE, Co) calculated the threshold cycle $(\mathrm{Ct})$ values. Finally, a pairwise comparison was performed by calculating the fold changes in gene expression from the raw threshold cycle using the $\left(2^{-\Delta \Delta c t}\right)$ method. The results of the method used to determine the relative expression of the genes of interest in this study were stored in a spreadsheet using PCR Array Data Analysis v3.3 (SABiosciences, Qiagen Company).

\section{Statistical analysis}

For the gene expression data, each sample was evaluated in triplicate. Student's t-test $(p<0.05)$ was applied to validate the homogeneity of the reaction. In the quantitative evaluation of the amplification process among groups, the computational program calculated the variation in the $\mathrm{Ct}$ of the study group in relation to the $\mathrm{Ct}$ of the CG expressed on a logarithmic (base 2) basis using the $2^{-\Delta \Delta C t}$ formula. Values that exceeded the threshold by three times (above or below) were considered relevant. 


\section{- Results}

\section{Evaluation of gene expression}

The evaluation results obtained for the expression of the 84 genes in cardiac tissues after intestinal IR in the IRG, OHB-IG, OHB-RG, and OHB-IRG were plotted in scatter plots, as shown in Figures 1 to 4, respectively.

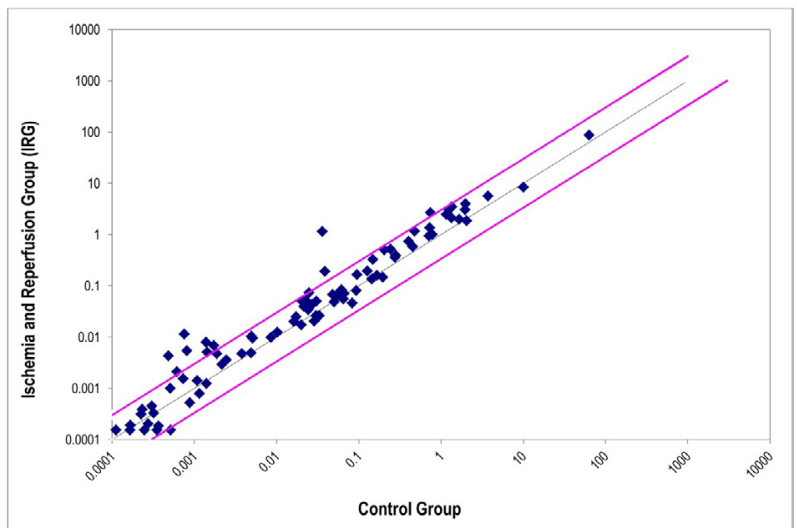

Figure 1 - Dispersion of the gene expression values of 84 genes associated with oxidative stress and antioxidant defense in cardiac tissue after intestinal ischemia and reperfusion; IRG specimens (ischemia/reperfusion without HBO) compared to CG (simulated control group without ischemia).

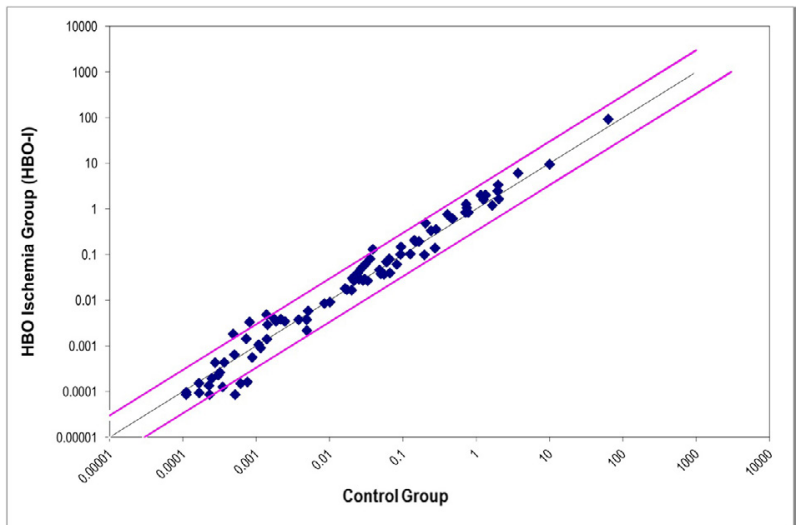

Figure 2 - Dispersion of the gene expression values of 84 genes associated with oxidative stress and antioxidant defense in cardiac tissue after intestinal IR; HBO-I specimens (HBO applied during ischemia) compared to CG (simulated control group without ischemia).

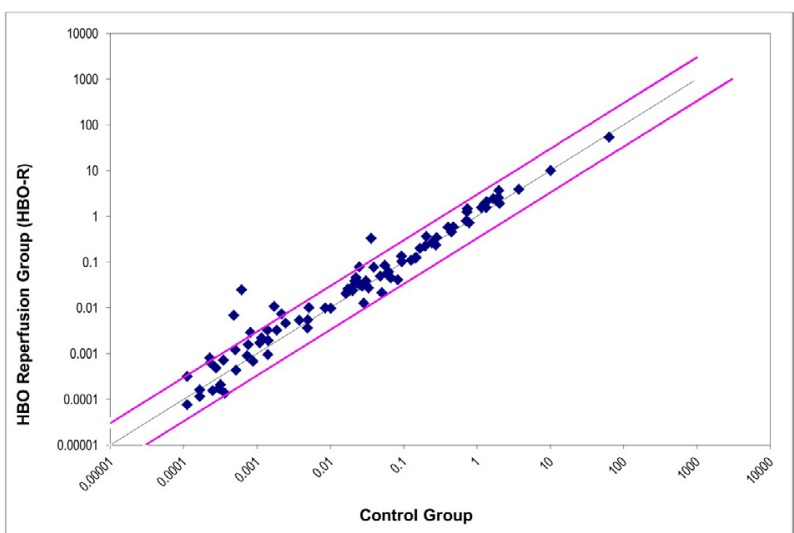

Figure 3 - Dispersion of the gene expression values of 84 genes associated with oxidative stress and antioxidant defense in cardiac tissue after intestinal IR; HBO-R specimens (HBO applied during reperfusion) compared to CG (simulated control group without ischemia).

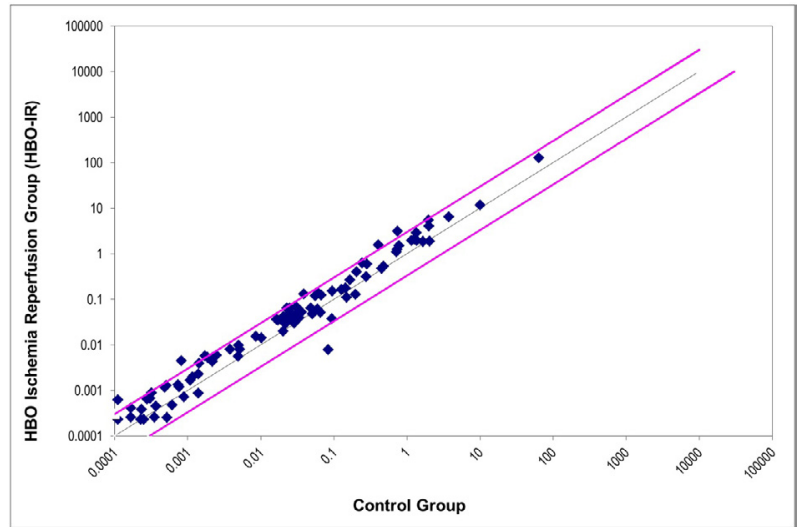

Figure 4 - Dispersion of the gene expression values of 84 genes associated with oxidative stress and antioxidant defense in cardiac tissue after intestinal ischemia and reperfusion; HBO-IR specimens (HBO applied during ischemia and reperfusion) compared to CG (simulated control group without ischemia).

In the intestinal tissues of the IRG, 73 (86.90\%) of the $84(100 \%)$ genes surveyed had a positive relative expression, and 11 (13.09\%) had a negative relative expression. Of the 73 genes with a positive expression, 37 (44.04\%) were hyperexpressed at levels three times above the normality threshold allowed by the algorithm (Table 1). The remaining 47 genes showed expression levels within the normal range or were hypoexpressed. 
Table 1 - Percent distribution of the expression of 84 genes according to the criteria of positive $(+)$ or negative (-) expression and hyper- (three times above the threshold) or hypo-expression (three times below the threshold) in the intestinal and cardiac tissues.

\begin{tabular}{ccccccc}
\hline & $\begin{array}{c}\text { Positive } \\
\text { Expression }\end{array}$ & $\begin{array}{c}\text { Negative } \\
\text { Expression }\end{array}$ & TOTAL & $\begin{array}{c}\text { Hyper } \\
\text { Expression }\end{array}$ & $\begin{array}{c}\text { Normal and } \\
\text { Hypo } \\
\text { Expression }\end{array}$ & TOTAL \\
\hline Intestine & $\begin{array}{c}73 \\
(86.90 \%)\end{array}$ & $\begin{array}{c}11 \\
(13.09 \%)\end{array}$ & $\begin{array}{c}84 \\
(100 \%)\end{array}$ & $\begin{array}{c}37 \\
(44.04 \%)\end{array}$ & $\begin{array}{c}47 \\
(55.95 \%)\end{array}$ & $\begin{array}{c}84 \\
(100 \%)\end{array}$ \\
Heart & 28 & 56 & 84 & 8 & 76 & 84 \\
& $(33.33 \%)$ & $(66.66 \%)$ & $(100 \%)$ & $(9.52 \%)$ & $(90.47 \%)$ & $(100 \%)$ \\
\hline
\end{tabular}

In the cardiac tissues of the group subjected to intestinal ischemia and reperfusion (IRG), 28 (33.33\%) genes had a positive expression, and 56 (66.66\%) genes had a negative expression. Among the 28 genes with positive expression, eight (9.52\%) were hyperexpressed. The remaining 76 genes showed expression within the normal range or hypoexpression (Table 1).

In the analysis of gene expression in the intestinal and cardiac tissues during intestinal ischemia and reperfusion (IRG), eight genes (Aass, Apoe, Fmc2, Nox4, Ptgs2, Rag2, Scd1, and S/c38a1) were positively expressed in both tissues. These genes were selected as the subjects of our study.

Thus, considering the expression of the eight selected genes in the cardiac tissues after the application of $\mathrm{HBO}$, we observed that $\mathrm{HBO}$ during ischemia (HBO-IG) promoted a decrease in the expression of the eight genes (100\%), HBO during reperfusion (HBO-RG) promoted a reduction in the expression of five of the genes (62.4\%), and HBO during ischemia and reperfusion (HBO-IRG) promoted a reduction in the expression of seven of the genes (87.5\%) (Table 2).

Table 2 - Results for eight genes expressed simultaneously in the intestinal and cardiac tissues. Values three times above the threshold (hyperexpressed) are indicated in red and with a positive sign (+); values three times below the threshold (hypoexpressed) are indicated in blue and with a negative sign (-); significant values within the triplicates of the samples are marked with asterisks $\left({ }^{*}\right)$ (Student's t test, $\mathrm{p} \leq 0.05$ ).

\begin{tabular}{ccccccccc}
\hline$\#$ & $\begin{array}{c}\text { Gene } \\
\text { Number }\end{array}$ & $\begin{array}{c}\text { Gene } \\
\text { acronym }\end{array}$ & Gene Name & IRG & HBO-I & HBO-R & HBO-IR \\
\hline 1 & NM_013930 & Aass & $\begin{array}{c}\text { Aminoadipate-semialdehyde } \\
\text { synthase }\end{array}$ & $+6.65^{*}$ & $+4.14^{*}$ & $+3.55^{*}$ & $+5.52^{*}$ \\
\hline 2 & NM_009696 & Apoe & Apolipoprotein E & $+3.60^{*}$ & +1.43 & $+1.99^{*}$ & $+4.23^{*}$ \\
\hline 3 & NM_018881 & Fmo2 & Flavin containing monooxygenase2 & $+4.93^{*}$ & $+3.39^{*}$ & $+1.97^{*}$ & $+3.36^{*}$ \\
\hline 4 & NM_015760 & Nox4 & NADPH oxidase 4 & $+5.73^{*}$ & $+3.48^{*}$ & +2.34 & +1.65 \\
\hline 5 & NM_011198 & Ptgs2 & $\begin{array}{c}\text { Prostaglandin-endoperoxide } \\
\text { synthase2 }\end{array}$ & $+3.94^{*}$ & $+2.34^{*}$ & $+6.22^{*}$ & $+3.32^{*}$ \\
\hline 6 & NM_009020 & Rag2 & Recombination activating gene2 & $+3.42^{*}$ & $-4.09^{*}$ & $+40.39^{*}$ & -1.28 \\
\hline 7 & NM_009127 & Scd1 & Stearoyl-Coenzyme A desaturase1 & $+31.73^{*}$ & $+2.28^{*}$ & $+9.13^{*}$ & +1.46 \\
\hline 8 & NM_134086 & Slc38a1 & Solute carrier family 38, member 1 & $+8.86^{*}$ & $+3.79^{*}$ & $+13.99^{*}$ & +2.40 \\
\hline
\end{tabular}




\section{- Discussion}

Intestinal ischemia and reperfusion injury promoted changes in the expression of oxidative stress-related genes at the original site as well as concomitantly at a distal site in the heart (Table 1). Eight genes were selected that were simultaneously expressed above the normality threshold allowed by the algorithm in the two tissues. HBO produced differential effects on the expression of these eight genes according to the time of application (Table 2).

\section{NADPH oxidase 4 (Nox4) gene}

The NADPH oxidase 4 (NOX4) protein is located intracellularly in the perinucleus and is a source of ROS 12,13 . This protein has a high expression level in cardiac tissue, although the degree of the difference in expression between the vessels and the myocardium is unclear. NOX4 presents a differentiated pattern of ROS production following binding of $\mathrm{NADPH}$ to its terminal carbon, which facilitates electron transfer, and thereafter via binding of the flavin adenine dinucleotide (FAD) to two heme residues and then to molecular oxygen; this process predominately acts as a source of hydrogen peroxide $\left(\mathrm{H}_{2} \mathrm{O}_{2}\right)$ and, to a lesser extent, as a source of superoxide anion $\left(\mathrm{O}_{2}\right)^{13,14}$. ROS production may increase through modulators of its expression, such as transforming growth factor $\beta$, angiotensin II, tumor necrosis factor alpha (TNF- $\alpha$ ), and shear stress. A decrease in expression is observed in the presence of platelet-derived growth factor (PDGF), hypoxia-induced factor 1 (HIF-1), and peroxisome proliferator-activated receptor (PPAR) gamma ${ }^{14,15}$. Our results showed that the Nox4 gene responded with hyperexpression during IR (IRG), which was characteristic of oxidative stress (Table 2). The application of $\mathrm{HBO}$ led to a reduction in oxidative stress during the three periods (HBO-I, HBO-R, and HBO-IR).
This reduction indicated that $\mathrm{HBO}$ modulated cardiac tissue protective factors.

\section{Flavin-containing monooxygenase 2 (Fmo2)} gene

The flavin-containing monooxygenase 2 (FMO2) enzyme is a component of monooxygenase systems with five isoenzymes located in the endoplasmic reticulum ${ }^{16,17}$. FMO2 acts on the oxidation of xenobiotics, such as amines, sulfides, iodine, sulfur, morphine, thiourea, propylthiouracil, thiophenol, hormones, and some phosphorus and selenium compounds. The enzyme acts via catabolic oxidation reactions and anabolic reactions to transform the metabolites into inactive compounds by detoxification catalyzed by transferases ${ }^{17,18}$. The prosthetic group of FAD is reduced to $F A D H_{2}$, and NADPH acts as the cofactor by serving as a hydrogen donor. $\mathrm{FADH}_{2}$ reacts with molecular oxygen to catalyze the oxidation reactions of various substances found in the body; the final products are hydrogen peroxide $\left(\mathrm{H}_{2} \mathrm{O}_{2}\right)$ and the superoxide anion $\left(\mathrm{OH}^{-}\right.$ ), which contribute to oxidative stress $^{18}$. In this study, hyperexpression of the $\mathrm{Fmo2}$ gene was observed in the IRG but was attenuated in the presence of $\mathrm{HBO}$ during the three periods (Table 2). This finding demonstrates the protective effect of HBO against oxidative stress in cardiac tissue.

Prostaglandin-endoperoxide synthase 2 (PTGS2) gene

The prostaglandin-endoperoxide synthase 2 (PTGS2) or cyclooxygenase 2 (COX2) protein catalyzes the conversion of arachidonic acid to prostaglandin G2 (PGG2), which is reduced by peroxidation to prostaglandin $\mathrm{H} 2$ (PGH2). Although it is not detectable in all tissues, PTGS2 synthesizes prostacyclin to induce the relaxation of smooth muscle cells, vasodilatation, and antiplatelet activity. PTGS2 
is stimulated by inflammation; it is expressed by monocytes and macrophages that are activated by cytokines (IL-1 and IL-6), tumor necrosis factor (TNF), and other mediators at sites of inflammation ${ }^{19,20}$. The activity of HBO was dependent on the period of application, and it reduced oxidative stress in the HBO-IG and $\mathrm{HBO}-\mathrm{IRG}$ in a manner that was suggestive of a probable anti-inflammatory and antioxidant effect during these periods. However, the increase of PTGS2 expression in the HBO-RG was associated with an unfavorable effect, showing that oxygen during reperfusion increased oxidative stress (Table 2).

\section{Aminoadipate-semialdehyde synthase (Aass) gene}

The $\alpha$-aminoadipic semialdehyde synthase (AASS) enzyme is present in the mitochondrial matrix. AASS is bifunctional and acts during the stages of irreversible catabolism of lysine degradation by lysine ketoglutarate reductase (LCR) and saccharopine dehydrogenase $(\mathrm{SDH})$ via two distinct metabolic pathways: mitochondrial saccharopine and pipecolic acid in peroxisomes. The enzyme degrades lysine to acetyl-CoA ${ }^{21,22}$. The metabolism of lysine by pipecolic acid via peroxisomes has been reported to promote oxidative stress by causing lipoperoxidation and apoptosis, decreasing the concentration of glutathione peroxidase, compromising the antioxidant defenses, and inhibiting $\mathrm{Na}^{+}$, $\mathrm{K}^{+}$-ATPase by ROS, with ionic changes in the membrane constituting an important factor of cellular damage ${ }^{22,23}$. Aass gene expression was reduced during the periods when the animals received HBO (Table 2). This lower need for lysine degradation, both for mitochondrial metabolism and in peroxisomes, indicates that $\mathrm{HBO}$ protects mitochondrial metabolism, leading to lower ROS formation in the peroxisomes.
Stearoyl-coenzyme A desaturase 1 (Scd1) gene

The stearoyl-coenzyme desaturase 1 (SCD1) enzyme participates in fatty acid metabolism, which catalyzes the biosynthesis of unsaturated fatty acids via desaturation, preferably using palmitoyl-CoA and steroylCoA as substrates. These monounsaturated acids (palmitoleic and oleic) are important components of membrane phospholipids and cholesterol esters. Biosynthesis increases the flow of substances through the membrane by decreasing the electrostatic interactions between lipid molecules, thereby altering their biophysical characteristics (i.e., arachidonic acid, which serves as a substrate for PTG2 synthesis $)^{24,25}$. Scd1 gene expression signals a greater need for SCD1 in the repair and substitution of saturated fatty acids to produce monounsaturated fatty acids, and it rebalances the fatty acids in the membrane that have been altered by the lipid peroxidation induced by oxidative stress ${ }^{25}$.

During the application of $\mathrm{HBO}$ to the groups, we observed a decrease in Scd1 expression during all three periods (HBO-I, HBO-R, and HBO-IR) (Table 2). This result can be interpreted as a protective action of $\mathrm{HBO}$ on the cardiac cellular structure, suggesting a reduced need for recomposition of the phospholipid layer determined by oxidative stress after intestinal IR.

\section{Recombination-activating gene 2 (Rag2) gene}

The RAG2 enzyme, which is a member of the peroxidases, acts in the immune system through a complex recombination system to randomly choose each of the VDJ (variablediversity-joining) segments. Immunoglobulins (Igs) (antibodies) consist of two types of light (L) chains (lambda and kappa) and one heavy (H) chain, which form isotypic and idiotypic regions. The idiotypic region is formed by the $\mathrm{L}$ and $\mathrm{H}$ chains, which are attached by disulfide 
bridges with sites at the ends and function in binding to antigenic substances. The isotypic region is formed by two $\mathrm{H}$ chains with the function of anchoring the Ig to the lymphocyte. This structure represents the generic structure of $\lg$, $\lg E$, $\lg A$, $\lg D$, or $\operatorname{lgM}^{26,27}$. The variable (V) domains of the light chains $\left(V_{L}\right)$ and heavy chains $\left(\mathrm{V}_{\mathrm{H}}\right)$ of the idiotypic ends can vary widely in amino acid composition, thereby making it possible to sequence thousands of regions encoding Igs from the DNA. The protein encoded by the Rag2 gene separates, shuffles, and forms new antibodies by recombination ${ }^{27,28}$. The presence of the hyperexpressed Rag 2 gene suggests intense antigen-antibody reactions in the cardiac tissue during intestinal IR (IRG). The application of $\mathrm{HBO}$ resulted in perioddependent action based on the decreased gene expression in the HBO-IG and HBO-IRG and the increase in gene expression in the HBO-RG (Table 2). Because the Rag2 gene is related to tissue immunogenicity, HBO likely plays an important role in the immunological defense of the cardiac tissue during ischemia and IR periods. Oxygen supply during the reperfusion period was associated with a greater immunological response to oxidative stress.

\section{Apolipoprotein E (Apoe) gene}

The apolipoprotein E (APOE) protein, which was originally described as linked to cholesterol metabolism, is a component of lipoproteins (very low-density lipoprotein (VLDL), intermediate-density lipoprotein (IDL), $L D L$, and high-density lipoprotein $(H D L))^{28}$. APOE participates in inflammatory processes as a modifying agent of the characteristics of the pro-inflammatory M1 macrophages, which increase cytokine expression and the generation of ROS and thus transform macrophages into the $M 2$ phenotype with antiinflammatory characteristics. The presence of the hyperexpressed Apoe gene signals a distal inflammatory process in the cardiac tissue ${ }^{29}$. We observed overexpression of the $A p o E$ gene in the IRG. In the groups that received HBO, gene expression in the cardiac tissue of the animals belonging to the HBO-IG and HBO-RG was decreased, indicating that $\mathrm{HBO}$ had an anti-inflammatory effect. When applied to the HBO-IRG, we found an increased expression of APOE, which indicated a pro-inflammatory action (Table 2).

\section{Solute carrier 38A1 (S/c38A1) gene}

The protein solute carrier $38 \mathrm{~A} 1$ (SLC38A1) is present in the heart, brain, and placenta. SLC38A1 acts as a carrier for solutes that control the absorption and efflux of substances, such as amino acids, sugars, nucleotides, inorganic ions, and drugs. Slc38A1 anditshomologsincludefacilitativetransporters as well as active transporters, including both cotransporters and energy exchangers ${ }^{30}$. SLC38A1 plays an important role in cellular defense and repair via the transport of these substances, which act in the detoxification and formation of other proteins ${ }^{30}$. Overexpression of the SIc38A1 gene demonstrated a greater need for the SLC38A1 protein in cardiac tissues in the presence of oxidative stress in the IRG. We observed a decrease in gene expression following exposure to $\mathrm{HBO}$ and, thus, lower activity of this protein in the HBO-IG and HBOIRG groups, suggesting a protective action of $\mathrm{HBO}$ on cardiac tissues against oxidative stress during these periods. This effect did not occur in the HBO-RG, where there was an increase in gene expression (Table 2 ) that indicated the harmful action of $\mathrm{HBO}$ when applied during this period.

Our results showed simultaneous positive expression of eight genes from the set of 84 genes associated with oxidative stress and defense in the intestine and heart, suggesting similar metabolic response pathways. The Nox4, Fmo2, Aass, and Scd1 genes showed 
reduced expression during the three application periods under the action of HBO. Their actions may be supported by prior knowledge of the decrease in ROS synthesis and the modification of modulators of inflammation in either the cytosol, endoplasmic reticulum, or cellular or nuclear membranes. The Ptgs2 (associated with mediators at inflammatory sites), Rag2 (associated with the immune system), and Slc38a1 (associated with cell defense and repair) genes yielded data that supported an interpretation consistent with other classical accounts that reperfusion was the most harmful phase in the tissue IR phenomenon. The Apoe gene (associated with inflammatory processes as a modifying agent of macrophage characteristics) was hyperexpressed during the application of $\mathrm{HBO}$ during ischemia and reperfusion (HBO-IRG).

This study contributes knowledge of the basic site and its distal repercussions to the topic of IR injury. We showed that the intestine, as the original site of IR injury, modified the expression of 28 genes associated with oxidative stress distally in the heart. Thus, the intestinal IR phenomenon may have acted as an ischemic preconditioning process for the heart.

The evaluation of eight genes with similar expression levels in the two tissues showed that the effects of HBO were dependent on the period in which the process was applied. This finding may explain the conflicting results in the literature on the effectiveness or efficacy of $\mathrm{HBO}$ in IR injury.

Other aspects require further investigation to reach a more consistent position that will allow gene expression to be used as a monitor of the severity or indicator of the treatment quality. One option is immunohistochemical confirmation of the proteins encoded by the genes and the selection and analysis of other genes made available by this method.

\section{Conclusions}

Hyperbaric oxygenation has several effects on the expression of genes associated with oxidative stress and antioxidant defense depending on the time of application. The application of $\mathrm{HBO}$ during the initial period of ischemia led to more favorable results in protecting the heart from the damaging effects of intestinal IR injury.

\section{References}

1. Gonzalez LM, MoeserAJ, Blikslager AT. Animal models of ischemia-reperfusion-induced intestinal injury: progress and promise for translational research. Am J Physiol Gastrointest Liver Physiol. 2015;308(2):G6375. doi: 10.1152/ajpgi.00112.2013.

2. Eltzschig HK, Collard CD. Vascular ischaemia and reperfusion injury. $\mathrm{Br}$ Med Bull. 2004;70:71-86. doi: 10.1093/bmb/ldh025.

3. Rodrigo $R$, Libuy $M$, Feliú $F$, Hasson D. Oxidative stress-related biomarkers in essential hypertension and ischemiareperfusion myocardial damage. Dis Markers. 2013;35(6):773-90. doi: 10.1155/2013/974358.

4. Shaw JJ, Psoinos C, Emhoff TA, Shah SA, Santry HP. Not just full of hot air: hyperbaric oxygen therapy increases survival in cases of necrotizing soft tissue infections. Surg Infect. 2014;15(3):328-35. doi: 10.1089/ sur.2012.135.

5. Yogaratnam JZ, Laden G, Madden LA, Seymour AM, Guvendik L, Cowen $M$, Greenman J, Cale A, Griffin S. Hyperbaric oxygen: a new drug in myocardial revascularization and protection? Cardiovasc Revasc Med. 2006;7(3):146-54. doi: 10.1016/j.carrev.2006.04.006.

6. Ondiveeran HK, Fox-Robichaud A. New developments in the treatment of ischemia/ reperfusion injury. Curr Opin Investig Drugs. 2001;2(6):783-91. PMID: 11572657.

7. Bennett $\mathrm{MH}$, Weibel S, Wasiak J, Schnabel A, French C, Kranke P. Hyperbaric oxygen therapy for acute ischaemic stroke. Cochrane Database Syst Rev. 2014;12(11):CD004954. doi: 10.1002/14651858.CD004954.pub3.

8. Buettner MF, Wolkenhauer D. Hyperbaric 
oxygen therapy in the treatment of open fractures and crush injuries. Emerg Med Clin North Am. 2007;25(1):177-88. doi: 10.1016/j.emc.2007.01.008.

9. Bertoletto PR, Ikejiri AT, Neto FS, Chaves JC, Teruya R, Bertoletto ER, Taha MO, Fagundes DJ. Oxidative stress gene expression profile in inbred mouse after ischemia/ reperfusion small bowel injury. Acta Cir Bras. 2012;27(11):773-82. doi: 10.1590/ S0102-86502012001100006.

10.Bertoletto PR, Chaves JC, Fagundes AT, Simoes RS, Oshima CT, Simoes MDE J, Fagundes DJ. Effect of different periods of hyperbaric oxygen on ischemia-reperfusion injury of rat small bowel. Acta Cir Bras. 2008;23(1):11-5. doi: 10.1590/S010286502008000100003.

11.Neto FS, Ikejiri AT, Bertoletto PR, Chaves JC, Teruya R, Fagundes DJ, Taha MO. Gene expression related to oxidative stress in the heart of mice after intestinal ischemia. Arq Bras Cardiol. 2014;102(2):165-73. doi: 10.5935/abc.20130240.

12.Chen F, Haigh S, Barman S, Fulton DJ. From form to function: the role of Nox4 in the cardiovascular system. Front Physiol. 2012;3(1):412. doi: 10.3389/ fphys.2012.00412.

13. Rabêlo LA, Souza VN, Fonseca LJ, Sampaio WO. Redox unbalance: NADPH oxidase as therapeutic target in blood pressure control. Arq Bras Cardiol. 2010;94(5):643-51. doi: 10.1590/S0066-782X2010000500018.

14.Panday A, Sahoo MK, Osorio D, Batra S. NADPH oxidases: an overview from structure to innate immunity-associated pathologies. Cell Mol Immunol. 2015;12(1):5-23. doi: 10.1038/cmi.2014.89.

15.Ostrowski RP, Tang J, Zhang JH. Hyperbaric oxygen suppresses NADPH oxidase in a rat subarachnoid hemorrhage model. Stroke. 2006;37(5):1314-8. doi: 10.1161/01. STR.0000217310.88450.c3.

16.Krueger SK, Williams DE. Mammalian flavincontaining monooxygenases: structure/ function, genetic polymorphisms and role in drug metabolism. Pharmacol Ther. 2005;106(3):357-87. doi: 10.1016/j. pharmthera.2005.01.001.

17.Francois A. Genetic variants of flavincontaining monooxygenases: consequences for drug metabolism (Thesis). University
College, London; 2014.

18. Eswaramoorthy S, Bonanno JB, Burley SK, Swaminathan S. Mechanism of action of a flavin-containing monooxygenase. Proc Natl Acad Sci USA. 2006;103(26):9832-7. doi: 10.1073/pnas.0602398103.

19.Smith WL, Langenbach R. Why there are two cyclooxygenase isozymes. J Clin Invest. 2001;107(12):1491-5. doi:0.1172/jci13271.

20.Batlouni M. Nonsteroidal anti-inflammatory drugs: cardiovascular, cerebrovascular and renal effects. Arq Bras Cardiol. 2010;94(4):556-63. doi: 10.1590/S0066782X2010000400019.

21.Sacksteder KA, Biery BJ, Morrell JC, Goodman BK, Geisbrecht BV, Cox RP, Gould SJ, Geraghty MT. Identification of the alphaaminoadipic semialdehyde synthase gene, which is defective in familial hyperlysinemia. Am J Hum Genet. 2000;66(6):1736-43. doi: 10.1086/302919.

22.Seminotti B, Fernandes CG, Leipnitz $G$, Amaral AU, Zanatta A, Wajner $M$. Neurochemical evidence that lysine inhibits synaptic $\mathrm{Na}+\mathrm{K}+-\mathrm{ATPase}$ activity and provokes oxidative damage in striatum of young rats in vivo. Neurochem Res. 2011;36(2):205-14. doi: 10.1007/s11064010-0302-4.

23.Dalazen GR, Terra M, Jacques CE, Coelho JG, Freitas R, Mazzola PN, Dutra-Filho CS. Pipecolic acid induces oxidative stress in vitro in cerebral cortex of young rats and the protective role of lipoic acid. Metab Brain Dis. 2014;29(1):175-83. doi: 10.1007/ s11011-013-9466-3.

24. Mauvoisin D, Mounier C. Hormonal and nutritional regulation of SCD1 gene expression. Biochimie. 2011;93(1):78-86. doi: 10.1016/j.biochi.2010.08.001.

25.Matsui H, Yokoyama T, Sekiguchi K, lijima D, Sunaga $H$, Maniwa $M$, Ueno $M$, Iso T, Arai M, Kurabayashi M. Stearoyl-CoA desaturase-1 (SCD1) augments saturated fatty acidinduced lipid accumulation and inhibits apoptosis in cardiac myocytes. PLoS One. 2012;7(3):e33283. doi: 10.1371/journal. pone.0033283.

26.Kudchodkar B, Jones H, Simecka J, Dory L. Hyperbaric oxygen treatment attenuates the pro-inflammatory and immune responses in apolipoprotein $E$ knockout mice. Clin Immunol. 2008;128(3):435-41. 
doi: 10.1016/j.clim.2008.05.004.

27.Lu C, Ward A, Bettridge J, Liu Y, Desiderio S. An autoregulatory mechanism imposes allosteric control on the $V(D) J$ recombinase by histone $\mathrm{H} 3$ methylation. Cell Rep. 2015;10(1):29-38. doi: 10.1016/j. celrep.2014.12.001.

28.Tarnus $E$, Wassef $H$, Carmel JF, Rondeau $P$, Roche $M$, Davignon J, Bernier L, Bourdon E. Apolipoprotein E limits oxidative stressinduced cell dysfunctions in human adipocytes. FEBS Lett. 2009;583(12):20428. doi: 10.1016/j.febslet.2009.05.016.

29.Baitsch D, Bock HH, Engel T, Telgmann R, Muller-Tidow C, Varga G, Bot M, Herz J, Robenek $\mathrm{H}$, von Eckardstein A, Nofer JR. Apolipoprotein $\mathrm{E}$ induces antiinflammatory phenotype in macrophages. Arterioscler Thromb Vasc Biol. 2011;31(5):1160-8. doi: 10.1161/atvbaha.111.222745.

30.Schlessinger A, Matsson P, Shima JE, Pieper U, Yee SW, Kelly L, Apeltsin L, Stroud RM,
Ferrin TE, Giacomini KM, Sali A. Comparison of human solute carriers. Protein Sci. 2010;19(3):412-28. doi: 10.1002/pro.320.

\section{- Acknowledgements}

To Operative Technique and Experimental Surgery Division, Department of Surgery and Molecular Gynecology Facilities (UNIFESP); Marcos Azevedo Junior, who is a biologist and PhD fellow in the Molecular Gynecology Postgraduate Program at UNIFESP, for the gene expression technology and advisory support; Ismael Dale Cotrin Guerreiro da Silva, Associate Professor, Department of Gynecology and Head of Molecular Gynecology Facilities at UNIFESP, for support with the analysis of the gene expression data.

\section{Correspondence:}

Frederico Somaio Neto

Rua João Vicente Ferreira, 1789

79824-030 Dourados - MS Brasil

Tel.: (55 67)3421-7171

fredericosomaio@gmail.com

Received: July 03, 2017

Review: Sept 05, 2017

Accepted: Oct 08, 2017
Conflict of interest: none

Financial source: none

${ }^{1}$ Research performed at Division of Surgical Techniques and Experimental Surgery, Department of Surgery, Universidade Federal de São Paulo (UNIFESP), Brazil. Part of PhD degree thesis, Postgraduate Program in Interdisciplinary Surgical Sciences, UNIFESP. Tutor: Djalma José Fagundes. 